
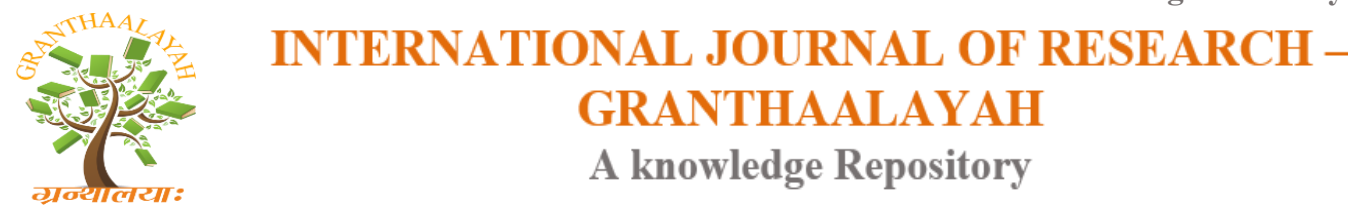

Science

\title{
INHIBITION OF CHOLESTEROL AND TRIGLYCERIDES SYNTHESIS BY COSTUS SPECIOSUS (KOEN. EX RETZ.) SMITH PLANT EXTRACT
}

\author{
C Bindu ${ }^{* 1,2}$, P. Rama Bhat ${ }^{3}$, B. C Girish ${ }^{4}$, G. Krishna Prasad ${ }^{5}$ \\ ${ }^{1}$ Affigenix Biosolutions Pvt Ltd., Bangalore -560099, Karnataka, INDIA \\ ${ }^{2}$ Research \& Development Centre, Bharathiar University, Coimbatore, Tamil Nadu, INDIA \\ ${ }^{3}$ PG Department of Biotechnology, Alvas College, Moodbidri, Karnataka, INDIA \\ ${ }^{4}$ Department of Pathology Veterinary College, Gokula, Hassan -573202, INDIA \\ ${ }^{5}$ Scigen Biopharma Pvt Ltd., International Biotech Park, Pune - 411057, INDIA
}

\begin{abstract}
Adipocyte dysfunction plays an important role in the obesity development. People with a body weight $\sim 45 \%$ heavier than the average body weight are at risk of death two times greater than the average body weight. The use of anti-obesity drugs have many side effects, so it is necessary to find the anti-obesity drug with low toxicity. Many microbial secondary metabolites and chemically synthesized anti-obesity drugs are available in the market with progressive side effects upon long term use of these medicines and drugs. Plant source antiobesity drugs are potentially sustained safe source of treatment. This ex vivo study was conducted to determine the activity of Costus speciosus plant extract in inhibiting triglycerides and cholesterol synthesis in HepG2 cells. Anti-obesity activity includes reduced formation of lipid droplet in HepG2 cells. The triglyceride levels and lipolytic activity by measuring cholesterol levels was performed based on commercially available kits.

This study suggested that the extract of C.speciosus inhibited triglycerides and cholesterol synthesis in HepG2 cell lines with inhibition of $89.25 \%$ and $52.01 \%$ respectively at the highest concentrations tested. The study also confirmed the anti-adipogenesis activity of plant extract and its potential in inhibiting the synthesis of triglycerides and cholesterol in HepG2 cell.
\end{abstract}

Keywords:

C.speciosus, plant extract, HepG2 cells, anti-obesity, cholesterol.

Cite This Article: C Bindu, P. Rama Bhat, B. C Girish, and Krishna Prasad, "INHIBITION OF CHOLESTEROL AND TRIGLYCERIDES SYNTHESIS BY COSTUS SPECIOSUS (KOEN. EX RETZ.) SMITH PLANT EXTRACT" International Journal of Research - Granthaalayah, Vol. 4, No. 3 (2016): 92-98.

\section{INTRODUCTION}

Obesity problem among developed and developing countries in the world is a serious health concern which lead to many other health complications. In India, diabetes, which is associated 
with the increase in over weight and obesity is a major lifestyle disease. Obesity is characterized by cellular fat content increasing both the number and size of adipocytes cells that undergo differentiation of cells in tissue preadipocyte (Lee, 2005).

Lipogenesis includes the process of fatty acid synthesis and subsequent triglyceride synthesis in the liver and adipose tissue. Synthesis occurs in the cytoplasm, while degradation occurs in the mitochondria(Kersten, 2001). Lipolysis is the decomposition of fat in fat cells, during the process of decomposition of the free fatty acids are released in the bloodstream and circulated in the body. Triglycerides undergo lipolysis (hydrolysis by lipases) into fatty acids. The enzyme Carnitine Palmitoyl Transferase lipolysis include-1 (CPT-1), Acyl CoA Oxidase-1 (ACO-1), uncoupling proteins (UCPS) (Chen, 2009). Excessive adipose tissue can cause insulin resistance, thereby increasing the risk of cardiovascular diseases and Type 2 diabetes, so it is important to inhibit proliferation and apoptosis preadipocyte network(Shu and Yen, 2013) .Various types of drugs have been studied and used, currently the focus is on herbal source to treat obesity because herbal remedies are natural, economical and has low side effects. Various types of herbs are already studied for antiobesity treatment and is proved safe materials and low toxicity (Mohamed, 2014).

Plant extracts as obesity drug candidates have high activity when the antilipase activity is high and no antilipase activity if it is less than 25\% (Etoundi, 2010). Lipase catalyses the hydrolysis of triglycerides that produces fatty acids (Choi, 2003). Ingredients or plant extracts with antiobesity properties can be tested ex vivo in HepG2 cells. Anti-obesity activity includes the reducing activity of the formation of triglycerides and cholesterol in adipocytes HepG2 cells. Therefore, the aim of this study is to evaluate the anti-obesity potential of C. speciosus in HepG2 cells by using the inhibition activity to triglyceride and cholesterol as parameters (Mohamed, 2014).

\section{MATERIALS AND METHODS}

The test materials used in the study is mainly $C$. speciosus plant aqueous extract. Other material include, Dimethylsulfoxide (DMSO) purchased from Merck Co. (Darmstadt, Germany). Dulbecco's modified Eagle's medium (DMEM - High glucose, Gibco), . The HepG2 cells were obtained from ATCC, lipase type II (Sigma EC 3.1.1.3), tris - $\mathrm{HCl}$ buffer, P nitrophenyl butyrate (PNPB), acetonitrile (Sigma Aldrich), triglycerides kit (Randox - TR - 210), cholesterol kit (Randox CH 200), high glucose DMEM , L-glutamine, sodium pyruvate (Biowest), Calf serum, fetal bovine serum (Juniper life sciences, India ), oleic acid $10 \mathrm{~mL}, 10 \mathrm{~mL}$ palmitic acid, phosphate buffer saline, DMSO 100\%, formaldehyde, lysis buffer, 70\% ethanol, trypsin EDTA, penicillin-streptomycin, Bovine Serum Albumin (BSA) (SIGMA). The instruments and equipments used in this study are the autoclave (Oriens, India), $\mathrm{CO}_{2}$ incubator (ESCO), laminar air flow (ESCO) cabinet, ninty six well plate, tips of various values( Tarsons, India), pipette 5 $\mathrm{ml}, 2 \mathrm{ml}, 15 \mathrm{ml}$ falcon, falcon $50 \mathrm{ml}, 5 \mathrm{ml}$ syringe, syringe filter, microtube $1.5 \mathrm{ml}$, cuvette 1 box, T flask $25 \mathrm{ml}, 75 \mathrm{ml} \mathrm{T}$ flasks (Taurus, India ).

\section{Costus specious plant extract preparation:}

Fresh aerial parts of Costus speciosus for the proposed work were collected from western ghats of Karnataka and authenticated by KVG college of Ayurveda, Sullia, Dakshina kannada, 
Karnataka India. The whole plant material was dried under shade, segregated for leaves, rhizome and shoot and mechanically reduced to moderate coarse powder and stored in air tight containers for further use in extraction process. The coarse powder $(100 \mathrm{~g})$ was mixed with $500 \mathrm{~mL}$ of distilled water and allowed to extract overnight at room temperature. The resultant dark green-brown mixture was filtered through filter paper (Whatman No. 1) and the filtrate was evaporated to dryness at $40^{\circ} \mathrm{C}$ under reduced pressure in a Rotavapor- $\mathrm{R}$ rotary evaporator. The resultant brown powder weighed $12 \mathrm{~g}$. The residue was redissolved in distilled water at a concentration of $0.2 \mathrm{~g} / \mathrm{ml}$ and kept frozen as one $\mathrm{ml}$ aliquots at $-20^{\circ} \mathrm{C}$ until required .This was termed the crude extract.

\section{HepG2 cell culture and adipocyte differentiation:}

HepG2 cells (human liver hepato cellular carcinoma cell line) was cultured in DMEM (Dulbecco's Modified Eagle Medium, Himedia) supplemented with 10\% FBS (Fetal Bovine Serum, Juniper lifescience) and $100 \mathrm{U} / \mathrm{mL}$ penicillin streptomycin (Invitrogen) then incubated for 24 hours at $37^{\circ} \mathrm{C}$ humidified atmosphere and $5 \% \mathrm{CO}_{2}$ (Liu, 2013). Cells then digested by trypsin-EDTA after confluent and harvested in $2500 \mathrm{rpm}$ centrifuge for 4 minutes. Cell cultures were grown in 6 well plate $\left(5 \times 10^{\wedge} 5\right.$ cells/well) then grown in DMEM containing $2 \%$ calf serum. Medium then discharged and supplemented with starving medium (DMEM $+1 \%$ antibiotic solution) then incubated for 24 hours. Starving medium then discharged and supplemented with induction medium (DMEM, 1:2 of 1mM palmitic acid: $1 \mathrm{mM}$ linoleic acid, BSA, and treatment). Costus speciosus used for the treatment in various concentrations $(500 \mu \mathrm{g} / \mathrm{mL} ; 250 \mu \mathrm{g} / \mathrm{mL} ; 125$ $\mu \mathrm{g} / \mathrm{mL} ; 62.5 \mu \mathrm{g} / \mathrm{mL} ; 31.25 \mu \mathrm{g} / \mathrm{mL}$ and $15.12 \mu \mathrm{g} / \mathrm{mL})$. Cells then incubated in $37^{\circ} \mathrm{C}$ humidified atmosphere and $5 \% \mathrm{CO}_{2}$.

\section{Oil red-O staining:}

The HepG2 cells after adipocyte differentiation and induction with C.speciosus extract were washed with $2 \mathrm{X}$ PBS. The cells then fixed for 30s with $70 \%$ ethanol in $2 \mathrm{X}$ PBS. Cells were washed with Milli Q water and stained for 2 hours by complete immersion in a working solution of Oil Red O (Milipore ECM950). Cells were then washed in 50\% ethanol for 3 seconds. Cell then observed under the inverted light Olympus microscope after the Oil-red $\mathrm{O}$ staining to compare the lipid droplet formation of normal cells and treated cells (Rizzatti, 2013)

\section{Triglycerides assay:}

The triglyceride level was measured in cell lysate after C. speciosus extract was added as sample. The measurement was performed according to Randox protocol using Randox TR 210 assay kit. The triglyceride level was determined after enzymatic hydrolysis with lipases (James, 2013). Briefly $450 \mu \mathrm{L}$ reagent with $5 \mu \mathrm{L}$ sample was added into the 24 -well plate then incubated in $37^{\circ} \mathrm{C}$ for 5 minutes. Sterile Milli Q water was used in blank well and standard reagent was used for standard wells. Standard reaction was prepared in seven different concentrations using serial dilution (4 mM / L;2 mM / L;1 mM / L;0.5 mM / L;0.25 mM / L;0.125 mM / L ;0.062 mM / $\mathrm{L}$ and $0.031 \mathrm{mM} / \mathrm{L}$ ). The absorbance was measured at $500 \mathrm{~nm}$ wave length. Triglyceride concentration was calculated using the below mentioned formula. The triglyceride inhibition activity was measured based on the triglyceride level in the positive control .

Triglyceride Concentration $=\{$ (absorbance of sample /absorbance of standard $) \times$ standard concentration( $\mathrm{mM} / \mathrm{L})$ \} 


\section{Cholesterol assay:}

Randox CH 200 kits were used for the quantitative in vitro determination of cholesterol level in cell lysate treated by C.speciosus extract based on standard. The cholesterol was determined after enzymatic hydrolysis and oxidation (Tietz,2006). Briefly $500 \mu \mathrm{L}$ mix reagent was added into multiwell plate.

A volume of $5 \mu \mathrm{L}$ standard solution was added into the standard well. Standard reaction was prepared in seven different concentrations using serial dilution $(5 ; 2.5 ; 1.25 ; 0.625 ; 0.31 ; 0.15$; and $0.07 \mathrm{mM} / \mathrm{L}$ ). The reaction was then incubated at $37^{\circ} \mathrm{C}$ for 5 minutes. The absorbance was measured at $500 \mathrm{~nm}$ wave length. The cholesterol concentration was calculated using the below mentioned formula .The cholesterol inhibition activity was measured based on the cholesterol level in the positive control.

Cholesterol concentration $(\mathrm{mg} \mathrm{dL})=\{($ absorbance of sample/ absorbance of standard $) \times$ standard concentration( $\mathrm{mM} / \mathrm{L})\}$

\section{Statistical analysis:}

Data was presented as mean concentrations and mean inhibition percentage of each triplicate sample. Statistical comparisons were performed using soft max 5.4.1 V. The measurement was performed according to Randox protocol using Randox TR 210 assay kit.

\section{RESULTS AND DISCUSSIONS}

Oil red staining of HepG2 cells confirmed excess lipid droplet formation in cells before treatment with plat extracts when compared to cells after treatment.

\section{Effect of Costus speciosus extract on level of triglycerides and \% TG inhibition}

The triglyceride measurement was performed according to Randox protocol using Randox TR 210 assay kit. TG level and activity of TG inhibition is shown in Table 1. The research results reveal that the effect of extract on the synthesis of triglycerides in HepG2 cells. The extract inhibit the production of triglycerides in HepG2 cells in a concentration dependent manner. The greatest inhibition of TG production shown at the concentration of $500 \mu \mathrm{g} / \mathrm{mL}$, while the lowest inhibition shown by the smallest concentration of $15.6 \mu \mathrm{g} / \mathrm{mL}$.

Table 1: Triglyceride level (mg/dl) and TG inhibition (\%) of Costus speciosus.

\begin{tabular}{|l|l|l|}
\hline & Samples TG level (mg/dL) & TG inhibition (\%) \\
\hline C. speciosus aqueous extract $500 \mu \mathrm{g} / \mathrm{mL}$ & 47.63 & 89.25 \\
\hline C. speciosus aqueous extract $250 \mu \mathrm{g} / \mathrm{mL}$ & 38.54 & 62.5 \\
\hline C. speciosus aqueous extract $125 \mu \mathrm{g} / \mathrm{mL}$ & 59.45 & 58.6 \\
\hline C. speciosus aqueous extract $62.5 \mu \mathrm{g} / \mathrm{mL}$ & 58.4 & 43.5 \\
\hline C. speciosus aqueous extract $31.25 \mu \mathrm{g} / \mathrm{mL}$ & 68.14 & 32.8 \\
\hline C. speciosus aqueous extract $15.6 \mu \mathrm{g} / \mathrm{mL}$ & 71.5 & 26.8 \\
\hline
\end{tabular}

\section{Effect of Costus speciosus extract on levels of cholesterol in HepG2 cells}

C. speciosus possess the inhibitory activity on cholesterol level in concentration dependent manner (Table 2). The total cholesterol level measurement is one of the most commonly examined measurements in lipid and exhibited varied levels of inhibition with relation to 
concentration of extracts. C. speciosus pocess the inhibitory activity on cholesterol level in concentration dependent manner.

Table 2: Cholesterol level (mg/dl) and cholesterol inhibition (\%) of C.speciosus extract

\begin{tabular}{|l|l|l|}
\hline & $\begin{array}{l}\text { Samples cholesterol } \\
\text { level (mg/dL) }\end{array}$ & $\begin{array}{l}\text { Cholestrol inhibition } \\
(\%)\end{array}$ \\
\hline C. speciosus aqueous extract $500 \mu \mathrm{g} / \mathrm{mL}$ & 56 & 52.01 \\
\hline C. speciosus aqueous extract $250 \mu \mathrm{g} / \mathrm{mL}$ & 44.56 & 48.24 \\
\hline C. speciosus aqueous extract $125 \mu \mathrm{g} / \mathrm{mL}$ & 52.14 & 45.12 \\
\hline C. speciosus aqueous extract $62.5 \mu \mathrm{g} / \mathrm{mL}$ & 66.25 & 30.25 \\
\hline C. speciosus aqueous extract $31.25 \mu \mathrm{g} / \mathrm{mL}$ & 31.25 & 24.95 \\
\hline C. speciosus aqueous extract $15.6 \mu \mathrm{g} / \mathrm{mL}$ & 40.85 & 12.87 \\
\hline
\end{tabular}

High fat diet associated with obesity correlated with elevated level of the cholesterol and triglycerides that caused adipogenesis (Song, 2013). Differentiation process of fat cell known as adipogenesis is controlled by hormonal induced coordinate expression and activation of peroxisome proliferator-activated receptor $\gamma(\mathrm{PPAR} \gamma)$ and CCAAT/enhancer-binding protein (C/EBP) (Rosen, 2000). Accumulation of intracellular triglycerides ultimately gives rise to the morphologically distinct fat cell (Terrand, 2009) Inhibiting the synthesis of cholesterol and triglycerides as anti-adipogenesis become an important role in antiobesity agent.

Several modes of action from natural compound known have potential to treat obesity, such as metabolic stimulants, appetite suppressants, starch blockers, glucose/insulin metabolism, lipid metabolism, and adipocyte-specific effects (Rayalam, 2008). In this ex vivo study using HepG2 as a invitro cell model showed that the extract of C.speciosus have potential antiobesity activity. It is shown from the results of studies that C.speciosus extract can inhibit the synthesis of TG and cholesterol in lipid forming HepG2 cells. Human hepatoma HepG2 cells is the most suitable and accessible human-derived cells that retain many of the biochemical functions of human liver parenchymal cells for the ex vivo study including anti-obesity screening (Inoue,2011) In this preliminary study, C.speciosus extract showed the higher inhibitory activity on TG and cholesterol synthesis that caused adipogenesis. It is well known theory that decreasing of TG level indicated the inhibition of adipogenesis which causes obesity (Liu, 2015). Adipocyte contain free cholesterol and will redistribute from the plasma membrane to the lipid droplet as the increasing of TG storage. The increasing of adipocyte cholesterol level was proportional with TG level (Chui, 2005). The potential of C.speciosus extract in preventing obesity is not exactly documented. This study provides a proof of concept to explore the plant extract ingredients selectively which can be potential anti obesity natural drug.

\section{CONCLUSIONS \& RECOMMENDATIONS}

This ex vivo study suggests that C.speciosus extract has potential anti-obesity effects by inhibit the cholesterol and TG that led adipogenesis in HepG2 cells. However, in vivo test in an animal model still needed to confirm the anti-obesity activity of the extract. The further mode of action test, preclinical and clinical studies should be pursued before pharmaceutical applications. 


\section{ACKNOWLEDGEMENTS}

We gratefully acknowledge technical support of all the scientists at Affigenix research center, Bangalore, India.

\section{REFERENCES}

[1] Lee W, Koh E, Woh J, Kim M, Park J, Lee K. Obesity: the role of hypothalamic AMPactivated protein kinase in body weight regulation. Int $J$ Biochem Cell Biol. 2005;37:2254-9.

[2] Kersten S. Mechanisms of nutritional and hormonal regulation of lipogenesis. EMBO Rep. 2001;2:282-

[3] Chen N, Bezzina R, Hinch E, Lewandowski P, Cameron-Smith D, Mathai M, et al. Green tea, black tea, and epigallocatechin modify body composition, improve glucose tolerance, and differentially alter metabolic gene expression in rats fed a high-fat diet. Nutr Res. 2009;29:784-93.

[4] Shu C, Yen G. Inhibitory effects of flavonoids on HepG2 preadipocytes for the mechanisms of proposed antiobesity. In: Shu C, Yen G, eds. A Research Article. Taiwan: National Chung Hsing University, Department of Food Science; 2013

[5] Mohamed G, Ibrahim S, Elkhayat E, El Dine R. Natural anti-obesity agents. B-FOPCU. 2014;52:269-84

[6] Etoundi C, Kuate D, Ngondi J, Oben J. Antiamylase, anti-lipase and antioxidant effects of aqueous extracts of some Cameroonian spices. J Nat Products. 2010;3:165-71.

[7] Choi S, Hwang J, Kim S. A colorimetric microplate assay method for high throughput analysis of lipase activity. J Biochem Mol Biol. 2003;3(4):417-20.

[8] Liu Z, Li Q, Huang J, Liang Q, Yan Y, Lin H, et al. Proteomic analysis of the inhibitory effect of epigallocatechin gallate on lipid accumulation in human HepG2 cells. Proteome Sci. 2013;11(32):1- 11

[9] Rizzatti V, Boschi F, Pedrotti M, Zoico E, Sbarbati A, Zamboni M. Lipid droplets characterization in adipocyte differentiated 3T3-L1 cells: size and optical density distribution. Eur J Histochem. 2013;57(24):159-62.

[10] James O, Godwin E, Otini I. Uvaria chamae (Annonaceae) plant extract neutralizes some biological effects of Naja nigricollis snake venom in rats. Br J Pharmacol Toxicol. 2013;4(2):41-50.

[11] Tietz. N. Clinical guide to laboratory test. In: Tietz N, eds. A Guide. 4th ed. Philadelphia: WB Saunders Co.; 2006

[12] Song Y, Park HJ, Kang SN, Jang SH, Lee SJ, Ko YG, et al. Blueberry peel extracts inhibit adipogenesis in 3T3-L1 cells and reduce high-fat diet-induced obesity. PLoS One. 2013;8(7):1-12.

[13] Rosen E, Walkey C, Puigserver P, Spiegelman B. Transcriptional regulation of adipogenesis. Genes Dev. 2000;14(11):1239-307.

[14] Terrand J, Bruban V, Zhou L, Gong W, Asmar Z, May P, et al. LRP1 controls intracellular cholesterol storage and fatty acid synthesis through modulation of Wnt signaling. J Biol Chem. 2009;284(1):381-3.

[15] Rayalam S, Fera M, Baile C. Phytochemicals and regulation of the adipocyte life cycle. $J$ Nutr Biochem. 2008;19:717-26. 
[16] Inoue N, Nagao K, Sakata K, Yamano N, Gunawardena P, Han SY, et al. Screening of soy protein-derived hypotriglyceridemic di-peptides in vitro and in vivo. Lipid Health Dis. 2011;10(85):1- 10.

[17] Liu Q, Wang YT, Lin L. New insights in the antiobese activity from Garcina mangostana. Food Funct. 2015;6(2):383-93.

[18] Chui P, Guan H, Lehrke M, Lazar M. PPAR regulates adipocyte cholesterol metabolism via oxidized LDL receptor 1. J Clin Invest. 2005;115(8):2245-56. 